\title{
The role of clinically significant antiphospholipid antibodies in systemic lupus erythematosus
}

\author{
M. Taraborelli', M.G. Lazzaroni ${ }^{1,2}$, N. Martinazzi ${ }^{2}$, M. Fredi $^{1}$, \\ I. Cavazzana ${ }^{1}$, F. Franceschini ${ }^{1}$, Angela Tincani ${ }^{1,2}$ \\ ${ }^{1}$ Rheumatology and Clinical Immunology, Spedali Civili of Brescia; \\ ${ }^{2}$ Rheumatology and Clinical Immunology, University of Brescia, Italy
}

\begin{abstract}
The objective is to investigate the role of clinically significant antiphospholipid antibodies (aPL) in a cohort of systemic lupus erythematosus (SLE) patients.

All SLE patients followed for at least 5 years and with available aPL profile at the beginning of the follow-up in our center were studied. Clinically significant aPL were defined as: positive lupus anticoagulant test, anti-cardiolipin and/or anti$\beta 2$ Glycoprotein $\mathrm{IgG} / \mathrm{IgM}>99^{\text {th }}$ percentile on two or more occasions at least 12 weeks apart. Patients with and without clinically significant aPL were compared by univariate (Chi square or Fisher's exact test for categorical variables and Student's $t$ or Mann-Whitney test for continuous variables) and multivariate analysis (logistic regression analysis). P values $<0.05$ were considered significant.

Among 317 SLE patients studied, 117 (37\%) had a clinically significant aPL profile at baseline. Such patients showed at univariate analysis an increased prevalence of deep venous thrombosis, pulmonary embolism, cardiac valvular disease, cognitive dysfunction and antiphospholipid syndrome (APS), but a reduced prevalence of acute cutaneous lupus and anti-extractable nuclear antigens (ENA) when compared with patients without clinically significant aPL. Multivariate analysis confirmed the association between clinically significant aPL and reduced risk of acute cutaneous lupus $[\mathrm{p}=0.003$, odds ratio (OR) 0.43$]$ and ENA positivity $(\mathrm{p}<0.001$, OR 0.37$)$, with increased risk of cardiac valvular disease $(\mathrm{p}=0.024$, OR 3.1$)$ and APS $(\mathrm{p}<0.0001$, OR 51.12). Triple positivity was the most frequent profile and was significantly associated to APS ( $<<0.0001$, OR 28.43). Our study showed that one third of SLE patients had clinically significant aPL, and that this is associated with an increased risk, especially for triple positive, of APS, and to a different clinical and serological pattern of disease even in the absence of APS.
\end{abstract}

SUMMARY

Key words: Systemic lupus erythematosus; antiphospholipid antibodies; antiphospholipid syndrome; thrombosis; valvulopathy. $52^{\text {nd }}$ SIR Congress, 2015.

\section{INTRODUCTION}

ystemic lupus erythematosus (SLE) is a systemic autoimmune disease with a heterogeneous spectrum of possible clinical and serological manifestations. Patients with SLE can produce a great variety of autoantibodies including antinuclear antibodies, anti-extractable nuclear antigen antibodies (ENA), anti-double stranded DNA antibodies (dsDNA), but also the so called antiphospholipid antibodies (aPL) such as anti-cardiolipin antibodies (aCL), anti- $\beta 2$ Glycoprotein I antibodies (a $\beta 2 \mathrm{GPI})$ or lupus anticoagulant (LA) (1). Antiphospholipid antibodies are the hallmark of antiphospholipid syndrome (APS), a condition that is characterized by pregnancy morbidity and/or thrombosis and that can be isolated (primary APS) or associated with other autoimmune diseases, in particular SLE (2). Antiphospholipid antibodies have been described in 20-40\% of SLE patients, with $50-70 \%$ of patients with SLE and aPL showing the clinical features of APS after 20 years of follow-up (3).

We recently described in a multiethnic cohort of SLE patients how the presence of clinically significant (persistent medium to high titer) aPL is a risk factor for irreversible organ damage accrual during a fifteenyear follow-up (4). Anyway the collabora-
Corresponding author

Mara Taraborelli

Piazzale Spedali Civili, 1

25123 Brescia

E-mail: mara.taraborelli@gmail.com 
tive nature of this retrospective study based on two Lupus registries did not allow us to analyze more deeply the differences between patients with and without significant aPL, in order to explain fully this different prognosis. Physicians dealing with SLE experience how patients with and without aPL show a different disease phenotype. Ünlü et al. (5) recently reviewed how SLE patients with aPL, compared with those without aPL, have a higher prevalence of thrombosis, pregnancy morbidity, but also cardiac valvular disease, pulmonary hypertension, livaedo reticularis, thrombocytopenia, hemolytic anemia, renal vascular lesions and moderate/severe cognitive impairment.

In that context we decided to investigate in a single center SLE cohort the role of clinically significant aPL beyond the risk of damage accrual.

\section{MATERIALS AND METHODS}

All the patients with a diagnosis of SLE, classified according to the 1997 American College of Rheumatology Criteria (6) and Systemic Lupus International Collaborating Clinics Criteria (7), who had been followed for at least 5 years and with complete aPL profiles available at the beginning of the follow-up (within \pm 1 year of registry entry) in the Lupus registry of our center, were identified and included in the present analysis. Their demographical, clinical and immunological characteristics were retrospectively collected by medical charts. Disease activity was measured by the SLE disease activity index (SLEDAI) $2 \mathrm{~K}(8)$ at the beginning of the follow-up in our center.

Clinically significant aPL were defined, according to the Updated Classification Criteria for APS (2), as: positive LA test, aCL $\operatorname{IgG} / \operatorname{IgM}$ antibodies $>99^{\text {th }}$ percentile and/or a 32 GPI $>99^{\text {th }}$ percentile on two or more occasions at least 12 weeks apart. All the immunological tests were performed in a single referral laboratory and were considered positive if confirmed at least twice during the follow-up (at least 12 weeks apart for aPL). Antinuclear antibodies were determined by indirect immunofluorescence on Hep-2 cell monolayers, ENA by counterimmunoelectrophoresis using calf and rabbit thymus and human spleen extracts, dsDNA by Farr's radioimmunological method or indirect immunofluorescence on Crithidia Luciliae substrate, total complement activity by the $50 \%$ complement hemolytic activity assay, $\mathrm{C} 3$ and $\mathrm{C} 4$ by nephelometry, aß2GPI IgG and IgM by immunoenzymatic assay (medium-high titers, $>99^{\text {th }}$ percentile, defined as $\geq 0.5$ optical density units), aCL IgG and IgM by immunoenzymatic assay (medium-high titers, $>99^{\text {th }}$ percentile, defined as $\geq 20 \mathrm{G}$ or $\mathrm{M}$ antiphospholipid units), LA by coagulation assay. For a 32 GPI in patients followed before the test was available, the first determinations during the follow-up were used. Categorical variables were reported as proportion and/or percentage. Continuous variables were reported as mean ( \pm standard deviation, SD) or median (range) value. For the univariate analysis the characteristics of patients with and without clinically significant aPL, and of patients with and without single, double and triple aPL positivity were compared by the Chi square or Fisher's exact test for categorical variables and by Student's $t$ test or Mann-Whitney-Wilcoxon test for continuous variables as appropriate. Variables that were found to be significantly associated with clinically significant aPL or triple aPL positivity at univariate analysis and that were considered relevant were included in the multivariate analysis by logistic regression analysis (StatView program version 5.1). $\mathrm{P}$ values $<0.05$ were considered significant. When significant, odds ratio (OR) with $95 \%$ confidence interval $(95 \% \mathrm{CI})$ was indicated.

This study was performed according to the principles of the Declaration of Helsinki and the registry was approved by the local Ethics Committee.

\section{RESULTS}

Three hundred and seventeen SLE patients (95\% female, 96\% Caucasian), prospectively followed in our Unit from 1972 to 
2014, were included in the analysis. The mean age at disease onset was $29( \pm$ SD 11$)$ years, the mean age at diagnosis $31( \pm \mathrm{SD}$ 11) years. The median follow-up was 14 (range 5-40) years with a median disease duration at the end of the follow-up of 19 (5-53) years.

One hundred and seventeen $(37 \%)$ patients had a clinically significant aPL profile at baseline. In particular 34 patients $(29 \%)$ had a single aPL positivity, $35(30 \%)$ a double aPL positivity and $48(41 \%)$ a triple positivity. Fifty-one of these patients (43\%) developed an APS during the follow-up. The comparison (by univariate analysis) of demographical, clinical and immunological characteristics during follow-up of patients with and without clinically significant aPL at baseline is shown in Tables I and II. Patients with clinically significant aPL showed a distinct clinical and serological profile. In particular, they had an increased prevalence of deep venous thrombosis (DVT), pulmonary embolism (PE), cardiac valvular disease, cognitive dysfunction and APS, but a reduced prevalence of acute cutaneous lupus (ACLE) compared to patients without clinically significant aPL. From a serological point of view, they also had a reduced prevalence of ENA, in particular anti-Ro/SSA, antiSmith and anti-U1RNP antibodies.

Multivariate analysis by logistic regression showed an association between clinically significant aPL and a reduced risk of ACLE $(\mathrm{p}=0.003$, OR $0.43,95 \% \mathrm{CI}: 0.43-0.24)$, and ENA positivity $(\mathrm{p}<0.001$, OR $0.37,95 \% \mathrm{CI}$ 0.21-0.66), while an increased risk of cardiac valvular disease $(\mathrm{p}=0.024$, OR 3.1, 95\% CI 1.16-8.36) and APS ( $<<0.0001$, OR 51.12, 95\%CI 12.47-209.5) was observed. The association with PE, DVT, cognitive dysfunction and specific ENA positivity (Ro, Sm, U1RNP) was not confirmed.

To understand better the role of clinically significant aPL, we compared the characteristics of patients with and without single, double and triple aPL positivity respectively. Univariate analysis showed an association between triple aPL positivity and PE (Fisher's exact test, $\mathrm{p}=0.012$, OR 8.061, 95\%CI 1.46-47.29), DVT (Fish- er's exact test, $\mathrm{p}<0.001$, OR 5.87, 95\%CI 2.42-14.25), and APS (Fisher's exact test, $\mathrm{p}<0.001$, OR 17.21, 95\%CI 7.96-37.69), whereas a negative association between triple aPL positivity and ACLE was observed (Chi square test, $\mathrm{p}=0.002$, OR 0.38 , 95\%CI 0.19-0.75). Multivariate analysis by logistic regression confirmed the positive association between triple aPL positivity and APS ( $<<0.0001$, OR 28.43, 95\% CI 9.71-83.21) and the negative association with ACLE ( $\mathrm{p}=0.02$, OR $0.39,95 \%$ CI $0.18-0.86)$. We did not find any association between single or double aPL positivity and disease characteristics.

\section{DISCUSSION AND CONCLUSIONS}

This study was focused on a cohort of SLE patients with complete aPL testing at baseline, followed for a median follow-up of 15 years. In this cohort, we observed that around one-third of patients had clinically significant aPL and that such autoantibody positivity was associated with APS, but also with a different clinical and serological profile even in the absence of APS.

The prevalence of clinically significant aPL in this monocentric cohort $(37 \%)$ is similar to that we recently described $(33 \%)$ in a multicentric cohort of SLE, where we demonstrated an association with an increased risk of damage accrual during a 15year follow-up (4). The prevalence of APS in our SLE cohort (19\%) is consistent with that previously described in the literature (20\%) (3).

The interest of our work was to identify any difference in SLE expression among patients with and without clinically significant aPL.

Antiphospholipid antibodies are well known to be associated with thrombotic events and adverse pregnancy outcome (2), and these events have been demonstrated to occur more frequently in SLE patients with aPL $(9,10)$. We were not able to document the pregnancy history of our patients as the information was not included in the registry. In any case, patients with clinically significant aPL had, as expected, an 
Table I - Demographical and clinical characteristics during follow-up of patients with and without clinically significant antiphospholipid antibodies at baseline (univariate analysis).

\begin{tabular}{|c|c|c|c|c|c|}
\hline Variable & $\begin{array}{l}\text { All patients } \\
(\mathrm{n}=317)\end{array}$ & $\begin{array}{l}\text { Patients with } \\
\text { significant aPL } \\
\text { (n=117) }\end{array}$ & $\begin{array}{l}\text { Patients without } \\
\text { significant aPL } \\
\text { (n=200) }\end{array}$ & $P$ value & OR $(95 \% \mathrm{Cl})$ \\
\hline Female sex, $\mathrm{n}(\%)$ & $300 / 317(95 \%)$ & $112 / 117(96 \%)$ & $188 / 200(94 \%)$ & 0.510 & NA \\
\hline Caucasian ethnicity, $n(\%)$ & $305 / 317(96 \%)$ & $113 / 117(97 \%)$ & $192 / 200(96 \%)$ & 0.794 & NA \\
\hline Age at onset (years), mean (SD) & $29(11)$ & $29(10)$ & $30(11)$ & 0.857 & NA \\
\hline Age at diagnosis (years), mean (SD) & $31(11)$ & $30(10)$ & $31(12)$ & 0.872 & NA \\
\hline Duration follow-up, median (range) & $14(5-40)$ & $15(5-39)$ & $14(5-40)$ & 1.466 & NA \\
\hline $\begin{array}{l}\text { Disease duration end of follow-up (years), } \\
\text { median (range) }\end{array}$ & $19(5-53)$ & $20(5-53)$ & $18(5-49)$ & 0.696 & NA \\
\hline SLEDAI-2K score at registry entry, mean (SD) & $12(6)$ & $12(6)$ & $12(6)$ & 0.364 & NA \\
\hline Fever, $n(\%)$ & $125 / 317(39 \%)$ & $50 / 117(43 \%)$ & $75 / 200(37 \%)$ & 0.357 & NA \\
\hline Fatigue, $n(\%)$ & $246 / 317(78 \%)$ & 90/117 (77\%) & $156 / 200(78 \%)$ & 0.824 & NA \\
\hline Sicca syndrome, $n(\%)$ & $176 / 317(55 \%)$ & $59 / 117(50 \%)$ & $117 / 200(58 \%)$ & 0.163 & $\mathrm{NA}$ \\
\hline Glomerulonephritis, n (\%) & 108/317 (34\%) & $37 / 117(32 \%)$ & $71 / 200(35 \%)$ & 0.482 & $\mathrm{NA}$ \\
\hline Arthritis, $n(\%)$ & $185 / 317(58 \%)$ & $63 / 117(54 \%)$ & $122 / 200(61 \%)$ & 0.212 & NA \\
\hline Myositis, n (\%) & $2 / 317(0.6 \%)$ & $1 / 117(0.8 \%)$ & $1 / 200(0,5 \%)$ & 0.700 & NA \\
\hline Raynaud's phenomenon, $n$ (\%) & 139/317 (44\%) & $50 / 117(43 \%)$ & $89 / 200(44 \%)$ & 0.760 & NA \\
\hline Photosensitivity, n (\%) & $150 / 317(47 \%)$ & $50 / 117(43 \%)$ & $100 / 200(50 \%)$ & 0.211 & NA \\
\hline Hair loss, $n(\%)$ & $84 / 317(26 \%)$ & $31 / 117(26 \%)$ & $53 / 200(26 \%)$ & 0.999 & NA \\
\hline Oral ulcers, $n(\%)$ & $113 / 317(36 \%)$ & $38 / 117(32 \%)$ & $75 / 200(37 \%)$ & 0.368 & NA \\
\hline Acute cutaneous lupus, $n$ (\%) & $176 / 317(55 \%)$ & $49 / 117(42 \%)$ & $127 / 200(63 \%)$ & $<0.001$ & $0.41(0.25-0.68)$ \\
\hline Subacute cutaneous lupus, $n$ (\%) & $17 / 317(5 \%)$ & $3 / 117(2 \%)$ & $14 / 200(7 \%)$ & 0.091 & NA \\
\hline Chronic cutaneous lupus, $n(\%)$ & $20 / 317(6 \%)$ & $4 / 117(3 \%)$ & $16 / 200(8 \%)$ & 0.105 & NA \\
\hline Purpura, $\mathrm{n}(\%)$ & $18 / 317(6 \%)$ & $6 / 117(5 \%)$ & $12 / 200(6 \%)$ & 0.746 & NA \\
\hline Pleurisy, n (\%) & $52 / 317(16 \%)$ & 18/117 (15\%) & $34 / 200(17 \%)$ & 0.708 & NA \\
\hline Lupic pneumonia, n (\%) & $9 / 317(3 \%)$ & $2 / 117(2 \%)$ & $7 / 200(3 \%)$ & 0.354 & NA \\
\hline Pulmonary embolism, $n(\%)$ & $7 / 317(2 \%)$ & $6 / 117(5 \%)$ & $1 / 200(0.5 \%)$ & 0.007 & $10.76(1.26-240.20)$ \\
\hline Deep venous thrombosis, $n(\%)$ & $29 / 317(9 \%)$ & 19/117 (16\%) & $10 / 200(5 \%)$ & 0.001 & $3.68(1.55-8.88)$ \\
\hline Pericarditis, $n$ (\%) & $41 / 317(13 \%)$ & $10 / 117(9 \%)$ & $31 / 200(15 \%)$ & 0.075 & $N A$ \\
\hline Cardiac valvular disease, $n(\%)$ & $28 / 317(9 \%)$ & $18 / 117(15 \%)$ & $10 / 200(5 \%)$ & 0.002 & $3.4(1.44-8.40)$ \\
\hline Pulmonary Hypertension, $\mathrm{n}(\%)$ & $4 / 317(1 \%)$ & $2 / 117(2 \%)$ & $2 / 200(1 \%)$ & 0.585 & $\mathrm{NA}$ \\
\hline Myocardial infarction, $n(\%)$ & $14 / 317(4 \%)$ & $6 / 117(5 \%)$ & $8 / 200(4 \%)$ & 0.637 & NA \\
\hline Stroke, $n(\%)$ & $34 / 317(11 \%)$ & $17 / 117(14 \%)$ & $17 / 200(8 \%)$ & 0.094 & $\mathrm{NA}$ \\
\hline Epilepsy, n (\%) & $24 / 317(8 \%)$ & $13 / 117(11 \%)$ & $11 / 200(5 \%)$ & 0.068 & NA \\
\hline Psychosis, $n(\%)$ & $12 / 317(4 \%)$ & $5 / 117(4 \%)$ & $7 / 200(3 \%)$ & 0.728 & NA \\
\hline Myelitis, $n(\%)$ & $2 / 317(0.6 \%)$ & $1 / 117(0.8 \%)$ & $1 / 200(0.5 \%)$ & 0.700 & $\mathrm{NA}$ \\
\hline Mood disorders, $n(\%)$ & $71 / 317(22 \%)$ & $29 / 117(25 \%)$ & $42 / 200(21 \%)$ & 0.435 & NA \\
\hline Cognitive dysfunction, $n(\%)$ & $38 / 317(12 \%)$ & $23 / 117(20 \%)$ & $15 / 200(7 \%)$ & 0.001 & $3.02(1.43-6.41)$ \\
\hline Peripheral neuropathy, $\mathrm{n}(\%)$ & $23 / 317(7 \%)$ & $10 / 117(9 \%)$ & $13 / 200(6 \%)$ & 0.498 & NA \\
\hline Antiphospholipid Syndrome, $n$ (\%) & $60 / 317(19 \%)$ & $51 / 117(44 \%)$ & $9 / 117(8 \%)$ & $<0.001$ & $16.39(7.30-37.98)$ \\
\hline Leukopenia $\left(<2000\right.$ cells $\left./ \mathrm{mm}^{3}\right), \mathrm{n}(\%)$ & $88 / 317(28 \%)$ & $27 / 117(23 \%)$ & $61 / 200(30 \%)$ & 0.154 & NA \\
\hline Lymphopenia (<1500 cells/mm³), n (\%) & $47 / 317(15 \%)$ & $20 / 117(17 \%)$ & $27 / 200(13 \%)$ & 0.385 & NA \\
\hline Thrombocytopenia $(100,000 \text { cells/mm } 3)^{3}, \mathrm{n}(\%)$ & $58 / 317(18 \%)$ & $23 / 117(20 \%)$ & $35 / 200(17 \%)$ & 0.632 & NA \\
\hline Haemolytic anaemia, $n(\%)$ & $23 / 317(7 \%)$ & $9 / 117(8 \%)$ & $14 / 200(7 \%)$ & 0.132 & NA \\
\hline
\end{tabular}

SLEDAI-2K, systemic lupus erythematosus disease activity index 2000; SD, standard deviation; aPL, antiphospholipid antibodies; OR, odds ratio; $95 \% \mathrm{Cl}, 95 \%$ confidence interval; NA, not applicable. 
Table II - Serological characteristics of patients with and without clinically significant antiphospholipid antibodies at baseline (univariate analysis).

\begin{tabular}{|l|l|l|l|l|l|}
\hline Variable & $\begin{array}{l}\text { All patients } \\
(\mathbf{n}=317)\end{array}$ & $\begin{array}{l}\text { Patients with } \\
\text { significant aPL } \\
(\mathbf{n}=117)\end{array}$ & $\begin{array}{l}\text { Patients without } \\
\text { significant aPL } \\
(\mathbf{n}=200)\end{array}$ & P value & OR (95\%Cl) \\
\hline Positivity for ANA, $n(\%)$ & $314 / 317(99 \%)$ & $116 / 117(99 \%)$ & $198 / 200(99 \%)$ & 0.897 & NA \\
\hline Positivity for ENA, $n(\%)$ & $184 / 317(58 \%)$ & $54 / 117(46 \%)$ & $130 / 200(65 \%)$ & 0.001 & $0.46(0.28-0.75)$ \\
\hline Positivity for Ro/SSA, $n(\%)$ & $138 / 317(43 \%)$ & $40 / 117(34 \%)$ & $98 / 200(49 \%)$ & 0.010 & $0.54(0.33-0.89)$ \\
\hline Positivity for La/SSB, $n(\%)$ & $34 / 317(11 \%)$ & $8 / 117(7 \%)$ & $26 / 200(13 \%)$ & 0.087 & NA \\
\hline Positivity for Sm, $n(\%)$ & $28 / 317(9 \%)$ & $7 / 117(6 \%)$ & $21 / 200(10 \%)$ & 0.001 & $0.24(0.09-0.63)$ \\
\hline Positivity for U1RNP, $n(\%)$ & $49 / 317(15 \%)$ & $11 / 117(9 \%)$ & $38 / 200(19 \%)$ & 0.023 & $0.44(0.20-0.95)$ \\
\hline Positivity for other ENA specificities, $n(\%)$ & $24 / 317(8 \%)$ & $9 / 117(8 \%)$ & $15 / 200(7 \%)$ & 0.950 & NA \\
\hline Positivity for anti-dsDNA, $n(\%)$ & $280 / 317(88 \%)$ & $103 / 117(88 \%)$ & $177 / 200(88 \%)$ & 0.901 & NA \\
\hline Reduced CH50, $n(\%)$ & $126 / 309(41 \%)$ & $50 / 114(44 \%)$ & $76 / 195(39 \%)$ & 0.399 & NA \\
\hline Reduced C3, $n(\%)$ & $144 / 317(45 \%)$ & $56 / 117(48 \%)$ & $88 / 200(44 \%)$ & 0.505 & NA \\
\hline Reduced C4, $n(\%)$ & $101 / 317(32 \%)$ & $44 / 117(38 \%)$ & $57 / 200(28 \%)$ & 0.093 & NA \\
\hline
\end{tabular}

ANA, antinuclear antibodies; ENA, anti-extractable nuclear antigen antibodies; Sm, anti-Smith antibodies; anti-dsDNA, anti double stranded DNA; CH50, 50\% complement hemolytic activity assay; aPL, antiphospholipid antibodies; OR, odds ratio; 95\%Cl, 95\% confidence interval; NA, not applicable.

increased prevalence of venous thrombosis (11). On the other hand, we did not observe an association with arterial events, such as myocardial infarction and stroke. This observation could be explained by the fact that other risk factors, such as traditional cardiovascular risk factors (hypercholesterolemia, hypertension, diabetes and metabolic syndrome) have been shown to be more prevalent in SLE patients and to participate, together with the inflammatory burden associated with disease activity, in the pathogenesis of premature atherosclerosis and arterial ischemic events (12-14).

Other clinical features have been associated with the presence of aPL and described in the clinical picture of systemic manifestations of APS (15). In our study, we confirmed the association with valvular heart disease, one of the possible manifestations of APS, which has been shown to be more prevalent in SLE patients with aPL compared to those without these autoantibodies $(16,17)$. We also found, as already described, that SLE with clinically significant aPL had more frequently cognitive dysfunction, even if a standardized cognitive examination was not routinely performed in our cohort, possibly limiting the diagnosis to more evident and severe cases $(18,19)$. No association was found with other manifestations classically related to aPL, such as thrombocytopenia and hemolytic anemia, but other autoantibodies such as antiplatelet antibodies (directed against platelet membrane glycoproteins) and anti-red blood cell antibodies (mainly directed against $\mathrm{Rh}$ molecules) are known to be involved in the pathogenesis of these manifestations $(20,21)$. The prevalence of pulmonary hypertension in our cohort was probably too low (1\%) to study any association with aPL $(22,23)$. The lack of association between venous thrombotic events, cognitive dysfunction and clinically significant aPL at multivariate analysis possibly suggests that these manifestations are not independent, but belong to the APS spectrum.

Acute cutaneous lupus is known to be associated with ENA, in particular anti-Ro and $\mathrm{Sm}$ (24). We were not expecting the inverse association between clinically significant aPL and ACLE or ENA, but we concluded that this observation reflects the fact that SLE patients with clinically significant aPL showed a different disease phenotype, possibly influenced by a different genetic background $(25,26)$.

Triple aPL positivity was the most frequent 
scenario among patients with clinically significant aPL. Such a profile, which is known to be a strong predictor of thrombotic events (27) and pregnancy morbidity (28), was the only one that showed an independent association with APS.

The limitations of our study are the retrospective design and the lack of information about pregnancy outcome and renal non-glomerular disease. Its strengths are the long follow-up and the use of recommended aPL testing in a single referral laboratory.

In conclusion, our study showed that SLE patients with clinically significant aPL have an increased risk, especially if triple positive, of developing APS, but also show a different clinical and serological profile even in the absence of APS.

Conflict of interests: the authors declare no conflict of interest.

\section{REFERENCES}

1. Sherer Y, Gorstein A, Fritzler MJ, Shoenfeld Y. Autoantibody explosion in systemic lupus erythematosus: more than 100 different antibodies found in SLE patients. Semin Arthritis Rheum. 2004; 34: 501-37.

2. Miyakis S, Lockshin MD, Atsumi T, Branch DW, Brey RL, Cervera R, et al. International consensus statement on an update of the classification criteria for definite antiphospholipid syndrome (APS). J Thromb Haemost. 2006; 4: 295-306.

3. Levine JS, Branch DW, Rauch J. The antiphospholipid syndrome. N Engl J Med. 2002; 346: 752-63.

4. Taraborelli M, Leuenberger L, Lazzaroni MG, Martinazzi N, Zhang W, Franceschini F, et al. The contribution of antiphospholipid antibodies to organ damage in systemic lupus erythematosus. Lupus 2016 [Epub ahead of print].

5. Ünlü $\mathrm{O}$, Zuily $\mathrm{S}$, Erkan D. The clinical significance of antiphospholipid antibodies in systemic lupus erythematosus. Eur J Rheumatology 2015. [Epub ahead of print].

6. Hochberg MC. Updating the American College of Rheumatology revised criteria for the classification of Systemic Lupus Eryhtematosus. Arthritis Rheum. 1997; 40: 1725.

7. Petri M, Orbai AM, Alarcón GS, Gordon C, Merrill JT, Fortin PR, et al. Derivation and validation of the Systemic Lupus International Collaborating Clinics classification criteria for systemic lupus erythematosus. Arthritis Rheum. 2012; 64: 2677-86.

8. Gladman DD, Ibanez D, Urowitz MB. Systemic lupus erythematosus disease activity index 2000. J Rheumatol. 2002; 29: 288-91.

9. Danowski A, de Azvedo MN, de Souza Papi JA, Petri M. Determinants of risk for venous and arterial thrombosis in primary antiphospholipid syndrome and in antiphospholipid syndrome with systemic lupus erythematosus. J Rheumatol. 2009; 36: 1195-9,

10. Mecacci F, Bianchi B, Pieralli A, Mangani B, Moretti A, Cioni R, et al. Pregnancy outcome in systemic lupus erythematosus complicated by anti-phospholipid antibodies. Rheumatology. 2009; 48: 246-9.

11. Wahl DG, Guillemin F, de Maistre E, Perret C, Lecompte T, Thibaut G. Risk for venous thrombosis related to antiphospholipid antibodies in systemic lupus erythematosus--a meta-analysis. Lupus. 1997; 6: 467-73.

12. Schoenfeld SR, Kasturi S, Costenbader KH. The epidemiology of atherosclerotic cardiovascular disease among patients with SLE: A systematic review. Semin Arthritis Rheum. 2013; 43: 77-95.

13. Bengtsson C, Ohman ML, Nived O. Cardiovascular event in systemic lupus erythematosus in northern Sweden: incidence and predictors in a 7-year follow-up study. Lupus. 2012; 21: 452-9.

14. Mikdashi J, Handwerger B, Langenberg P, Miller M, Kittner S. Baseline disease activity, hyperlipidemia, and hypertension are predictive factors for ischemic stroke and stroke severity in systemic lupus erythematosus. Stroke. 2012; 382: 281-5.

15. Taraborelli M, Andreoli L, Tincani A. Much more than thrombosis and pregnancy loss: the antiphospholipid syndrome as a 'systemic disease'. Best Pract Res Clin Rheumatol. 2012; 26: 79-90.

16. Silbiger JJ. The cardiac manifestations of antiphospholipid syndrome and their echocardiographic recognition. J Am Soc Echocardiogr. 2009; 22: 1100-8.

17. Zuily S, Regnault V, Selton-Suty C, Eschwège $\mathrm{V}$, Bruntz JF, Bode-Dotto E, et al. Increased risk for heart valve disease associated with antiphospholipid antibodies in patients with systemic lupus erythematosus: meta-analysis of echocardiographic studies. Circulation. 2011; 124: 215-24.

18. Tektonidou MG, Varsou N, Kotoulas G, Antoniou A, Moutsopoulos HM. Cognitive deficits in patients with antiphospholipid syndrome: association with clinical, laboratory, and brain magnetic resonance imaging findings. Arch Intern Med. 2006; 166: 2278-84.

19. Coín MA, Vilar-López R, Peralta-Ramírez I, Hidalgo-Ruzzante N, Callejas-Rubio JL, Ortego-Centeno N, et al. The role of antiphos- 
pholipid autoantibodies in the cognitive deficits of patients with systemic lupus erythematosus. Lupu. 2015; 24: 875-9.

20. Macchi L, Rispal P, Clofent-Sanchez G, Pellegrin JL, Nurden B, Leng B et al. Anti-platelet antibodies in patients with systemic lupus erythematosus and the primary antiphospholipid antibody syndrome: their relationship with the observed thrombocytopenia. Br J Haematol. 1997; 98: 336-41.

21. Giannouli S, Voulgarelis M, Ziakas PD, Tzioufas AG. Anaemia in systemic lupus erythematosus: from pathophysiology to clinical assessment. Ann Rheum Dis 2006; 65: 144-8.

22. Lee JH, Im Cho K. Arterial stiffness, antiphospholipid antibodies, and pulmonary arterial hypertension in systemic lupus erythematosus. J Cardiol. 2014; 64: 450-5.

23. Zuily S, Wahl D. Pulmonary hypertension in antiphospholipid syndrome. Curr Rheumatol Rep. 2015; 17: 478.
24. Okon LG, Werth VP. Cutaneous lupus erythematosus: diagnosis and treatment. Best Pract Res Clin Rheumatol. 2013; 27: 391-404.

25. Niewold TB. Advances in lupus genetics. Curr Opin Rheumatol. 2015; 27: 440-7.

26. Fredi M, Tincani A, Yin H, Delgado-Vega AM, Borghi MO, Meroni PL, et al. IRF5 is associated with primary antiphospholipid syndrome, but is not a major risk factor. Arthritis Rheum. 2010; 62: 201-2.

27. Pengo V, Biasiolo A, Pegoraro C, Cucchini U, Noventa F, Iliceto S. Antibody profiles for the diagnosis of antiphospholipid syndrome. Thromb Haemost. 2005; 93: 1147-52.

28. Ruffatti A, Salvan E, Del Ross T, Gerosa M, Andreoli L, Maina A, et al. Treatment strategies and pregnancy outcomes in antiphospholipid syndrome patients with thrombosis and triple antiphospholipid positivity. A European multicenter retrospective study. Thromb Haemost. 2014; 112: 727-35. 